\title{
Adaptive response to pneumonectomy in puppies
}

\author{
WILLIAM M THURLBECK, WAYNE GALAUGHER, AND JOAN MATHERS \\ From the Department of Pathology, University of British Columbia, Vancouver, British Columbia, Canada
}

ABSTRACT When left pneumonectomy was performed on 9-week-old puppies, the right lung increased in weight, volume, surface area, and number of alveoli so that at age 20 weeks these variables were the $\omega^{\circ}$ same as those of both lungs of control animals and significantly larger than those of the right lung of control animals. The adaptive response of the right lung after pneumonectomy was greater in the $\stackrel{\sim}{\perp}$ lower lobe than in the middle or cardiac lobes. The number of alveoli per $\mathrm{ml}$ and the average inter- $\frac{\text { O }}{2}$ alveolar wall distance, hence the surface to volume ratio, was the same in both lungs of control $\rightarrow$ animals and the same in the cardiac, middle, and lower lobes of their right lungs.

After pneumonectomy in experimental animals, the contralateral lung increases in volume, weight, collagen content, protein and deoxyribonucleic acid (DNA) to approximate to the values in both lungs of control animals. ${ }^{1-12}$ There are conflicting views on the effect of pneumonectomy on alveolar multiplication, ${ }^{3} 468101113-19$ and these have been reviewed elsewhere. ${ }^{19}$ In part, the reason for the controversy stems from older and less rigorous methods of counting alveoli, but also results from inherent practical and theoretical difficulties in counting alveoli and calculating alveoli per unit volume. ${ }^{19} 20$ In general, alveolar surface area increases directly with lung volume after pneumonectomy rather than to the $2 / 3$ power which would be expected by simple overinflation, suggesting increased complexity of alveolar surface. This could be brought about either by lengthening of alveolar septa ${ }^{18} 19$ or increased alveolar number. ${ }^{19} \mathrm{We}$ found that, after pneumonectomy in 10-week-old rabbits, the contralateral lung increased in volume, surface area, and alveolar number to the levels of these variables in both lungs of controls four weeks later. ${ }^{10}$ In rats, the adaptive response was less complete; when pneumonectomy was performed at 12 weeks of age, the relative response to the contralateral lung was less than when pneumonectomy was performed at 4 to 8 weeks of age. ${ }^{19}$ Statistically significant alveolar multiplication did not occur when pneumonectomy was performed at 12 weeks of age.

The only previous study in dogs showed that the average alveolar diameter was increased in the contralateral lung of two adult dogs after pneumonec-

Address for reprint requests: Professor WM Thurlbeck, Department of Pathology, University of British Columbia, 2211 Westbrook Mall, Vancouver, Britisn Columbia V6T 1W5, Canada. tomy but not when pneumonectomy was performed $\stackrel{\infty}{\rightarrow}$ on three puppies. ${ }^{14}$ These data suggest that alveolar multiplication occurs after pneumonectomy in puppies but not in adult dogs. Dogs are highly suitable animals for the study of lung mechanics and gas exchange and we wondered what the adaptive $\stackrel{\circ}{\mathbb{Q}}$ response would be to pneumonectomy performed in $\overrightarrow{\vec{P}}$ puppies. In this paper we describe the morphological findings.

\section{Methods}

Left pneumonectomy was performed on four male $\frac{0}{2}$ and four female mongrel puppies, 9 weeks old. $\dot{\sigma}$ Three male and four female mongrel puppies of the 3 . same age, litter mates of the experimental animals, $\delta$ underwent similar anaesthesia and a chest wall incision without entering the pleural cavity. It 0 has been shown that collapse of the lung will induce cellular multiplication and weight increase in the contralateral lung. ${ }^{72122}$ All animals were of approximately the same weight at the time of operation. or At the age of 20 weeks, the animals underwent tests $N$ of pulmonary mechanics and gas exchange. While $N$ still anaesthetised, the animals were exsanguinated. The postmortem mechanical properties of the lungs were then studied. Four pneumonectomy specimens, at age 9 weeks, all the contralateral lungs of the $\stackrel{\oplus}{\rightarrow}$ pneumonectomised animals and three left and seven $T$ right lungs of the controls at 20 weeks were excised and weighed. The right upper lobe was removed, $\mathbb{\mathbb { D }}$ distended at a transpulmonary pressure of $25 \mathrm{~cm}$ of $\mathbb{\mathbb { D }}$ saline and its volume measured by water displacement. We intended to make biochemical measurements from this lobe, but there was a technical mishap. The rest of the right lung and the left lungs were 
fixed for at least two days with intra-bronchial formalin at a transpulmonary pressure of $25 \mathrm{~cm}$ of formalin. Lung volumes were measured by water displacement and the lobes cut into sagittal slices. The volume proportions of parenchyma (tissue less than $1 \mathrm{~mm}$ in diameter) and non-parenchyma (tissue greater than $1 \mathrm{~mm}$ in diameter) were then determined by point counting the slices of lung. The measurements listed below were made in parenchyma and corrected to the whole lung. Three random blocks were taken from the mid-sagittal slice of each lobe of the left lung. Sections were cut at $7 \mu \mathrm{m}$ thickness and stained with haematoxylin and eosin. Shrinkage was determined and all values refer to dimensions of fixed lung volume. The slides were randomised and coded. The following measurements were made on the lungs using standard techniques or minor modifications. ${ }^{19}$

Inter-alveolar wall distance $\left(\mathrm{L}_{\mathrm{m}}\right)$, volume proportion of alveolar air, volume proportion of alveolar duct air (the "core" of air internal to alveoli) and the number of alveoli per unit area. Alveolar surface area $^{23}$ and the total number of alveoli and average alveolar volume were calculated using standard methods with the assumption that the alveolar shape factor was $1.55^{24}$ and that the distribution of characteristic linear dimensions of alveoli was normal. No correction was made for thickness of histological slides. Total alveolar number was projected to the fixed lung volume plus the saline filled right upper lobe.

Student's $t$ test was used for statistical analysis.

\section{Results}

The findings in the right lung of the "pneumonectomy" animals were compared with the right lung and with both lungs of control animals (figure). This shows that the right lungs of the pneumonectomy animals had significantly larger volumes, alveolar surface area, and total number of alveoli than the right lungs of the controls and that there was a trend for alveolar duct proportion to be increased in the pneumonectomy animals. Alveolar dimensions were not different between the two groups and alveolar surface area increased directly with lung volumes in the pneumonectomy animals. There were no statistically significant differences between the right lungs of pneumonectomy animals and both lungs of the controls. There was a trend for the two lungs of the control animals to have more alveoli than the single contralateral lung in the pneumonectomy animals.

Table 1 shows a comparison of the dimensions of the structures in the right and left lungs of controls and shows that there are no differences. The right lung was $63.6 \%$ larger than the left lung and therefore the total surface area and total number of alveoli were correspondingly higher in the right lung. We have also recalculated our data assuming that the four left lungs of the control animals not subjected to morphometry had the same number of alveoli per unit volume and $L_{m}$ as their right lungs. The results are exactly the same as when the comparison was made between pneumonectomy animals and both
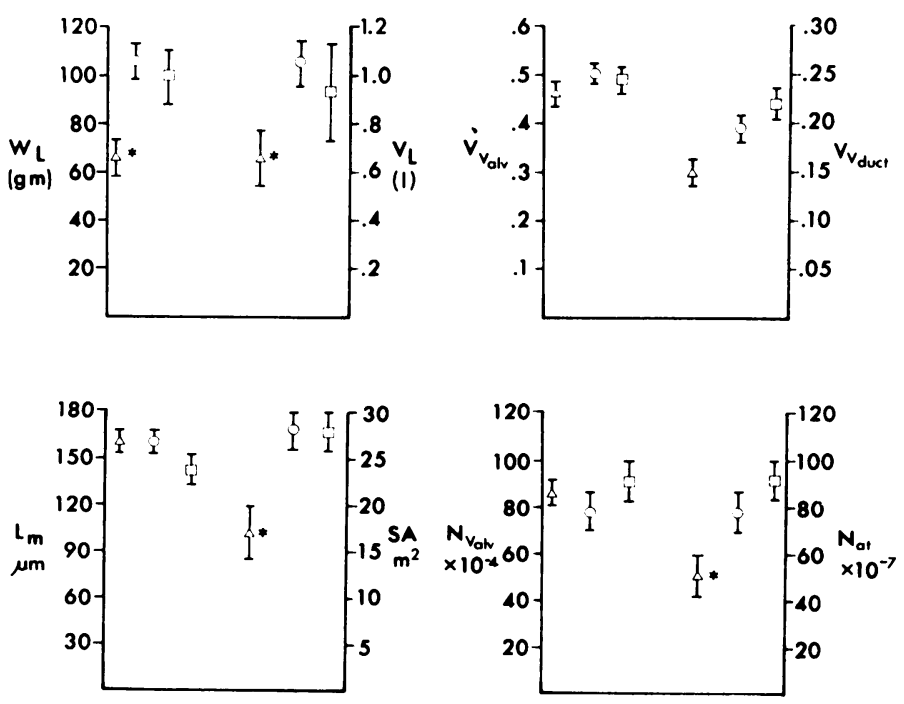

Figure Dimensions of the right lung of animals $(\triangle)$, the right lung of animals undergoing pneumonectomy $(O$,$) and$ both lungs of control animals $(\square)$ are compared. Bars represent $\pm 1 S E$. The variables are: lung weight $\left(W_{L}\right)$, lung volume distended at a transpulmonary pressure of $25 \mathrm{~cm}$ formalin $\left(V_{L}\right)$, volume proportion of alveoli $\left(V_{v}\right.$ alv $)$, volume proportion of "alveolar ducts" $V_{v}$ act $)$, average interalveolar wall distance $(\mathrm{Lm})$, alveolar surface area $(S A)$ number of alveoli per $\mathrm{ml}\left(N_{v}\right.$ alv $)$, and total number of alveoli $\left(N_{a t}\right)$. *.4steris $k$ indicates a difference, significant at p 0.05 or less. 
Table 1 Morphometric variables in control lungs in 20-week-old animals and in the left lung excised at 9 weeks of age $($ mean $\pm S E M)$

\begin{tabular}{|c|c|c|c|}
\hline & $\begin{array}{l}\text { Right lung (controls) } \\
20 \text { Weeks } n=7\end{array}$ & $\begin{array}{l}\text { Left lung (controls) } \\
20 \text { Weeks } n=3\end{array}$ & $\begin{array}{l}\text { Left lung pneumonectomy } \\
9 \text { Weeks } n=4\end{array}$ \\
\hline Lung volume (ml) & $627 \pm 84$ & $383 \pm 63$ & $113 \pm 15$ \\
\hline Interalveolar wall distance $(\mu \mathrm{m})$ & $158 \pm 7$ & $136 \pm 11$ & $141 \pm 5$ \\
\hline Volume proportion of alveoli & $0.46 \pm 0.02$ & $0.50 \pm 0.04$ & $0.47 \pm 0.01$ \\
\hline Volume proportion of ducts & $0.15 \pm 0.03$ & $0.20 \pm 0.03$ & $0.28 \pm 0.01$ \\
\hline Alveoli per $\mathrm{ml}\left(\times 10^{-3}\right)$ & $876 \pm 60$ & $931 \pm 29$ & $1100 \pm 76$ \\
\hline Volume proportion of parenchyma & $0.76 \pm 0.03$ & $0.82 \pm 0.05$ & $0.85 \pm 0.1$ \\
\hline Volume proportion of non-parenchyma & $0.24 \pm 0.03$ & $0 \cdot 18 \pm 0.05$ & $0 \cdot 15 \pm 0.1$ \\
\hline
\end{tabular}

Table 2 Lung volumes and lobar comparisons of number of alveoli per $m l$ and average interalveolar wall distance in the right lung

\begin{tabular}{|c|c|c|c|c|c|}
\hline \multicolumn{2}{|c|}{ Right lung volume $(\mathrm{ml})$} & \multicolumn{2}{|c|}{ Number of alveoli per $\mathrm{ml}\left(\times 10^{-3}\right)$} & \multicolumn{2}{|c|}{ Average interalieolar wall distance $(\mu \mathrm{m})$} \\
\hline $\begin{array}{l}\text { Control } \\
n=7\end{array}$ & $\begin{array}{l}\text { Pneumonectomy } \\
n=8\end{array}$ & $\begin{array}{l}\text { Control } \\
n=7\end{array}$ & $\begin{array}{l}\text { Pneumonectomy } \\
n=8\end{array}$ & $\begin{array}{l}\text { Control } \\
n=7\end{array}$ & $\begin{array}{l}\text { Pneumonectomy } \\
n=8\end{array}$ \\
\hline $627 \pm 84$ & $1062 \pm 97$ & $\begin{array}{ll}\text { Cardiac } & 962.9 \pm 129.7 \\
\text { Middle } & 748 \cdot 5 \pm 61 \cdot 5 \\
\text { Lower } & 903.8 \pm 48.8\end{array}$ & $\begin{array}{l}623 \cdot 7 \pm 84 \cdot 8^{*} \\
682 \cdot 4 \pm 80 \cdot 1 \dagger \\
902 \cdot 8 \pm 55 \cdot 3\end{array}$ & $\begin{array}{l}159 \pm 13 \\
157+11 \\
151 \pm 7\end{array}$ & $\begin{array}{l}166 \pm 12 \dagger \\
155 \pm 11 \\
145 \pm 7\end{array}$ \\
\hline
\end{tabular}

* Different from control $\mathrm{p}<0.05$, different from lower lobe pneumonectomy $\mathrm{p}<0.01$.

$\dagger$ Different from lower lobe pneumonectomy, $p<0.05$.

lungs of the control animals as was illustrated in the figure. Table 1 also compares the dimensions of structures in left lungs at pneumonectomy in 9-weekold puppies with left lungs in the 20 -week-old controls. Once again the dimensions of structures are the same but lung volume increased by $339 \%$, surface area by $362 \%$, and total alveolar number by $288 \%$.

Table 2 gives a comparison of the dimensions in the lobes of the right lung. There are no differences between the lobes in the controls. In pneumonectomy animals there were fewer alveoli per $\mathrm{ml}$ in middle $(p<0.05)$ and cardiac $(p<0.01)$ lobes compared with the lower lobe, and the inter-alveolar wall distance was greater in the cardiac lobe $(p<0.05)$ than in the lower lobe suggesting a greater adaptive response in the lower lobe. The cardiac lobe in pneumonectomy animals had fewer alveoli per unit volume than the controls $(p<0.05)$ suggesting that the adaptive response was less complete in this lobe.

\section{Discussion}

Our data show that in the dog, as in the rat and rabbit, after pneumonectomy the contralateral right lung increases in lung weight, lung volume, surface area, and total alveolar number. These values closely approximate to those of both lungs of the control animals, and these variables were also significantly greater than in the single left lung of control animals.
The adaptive responses were almost as complete as in the rabbit, ${ }^{10}$ in that the total number of alveoli in the contralateral lung was less than in both lungs of the controls, but not significantly so. The argument about the significance of alveolar number persists ${ }^{18} 19$ and has been discussed previously. ${ }^{19}$ Surface area increased directly with lung volume and we interpret this to mean increased alveolar surface complexity brought about by formation of new alveoli. Alternatively, alveolar walls may become more complex ${ }^{18}$ but we could find no evidence for this. If alveolar walls elongated to produce increased surface area, then the volume proportion of alveolar air would increase and the volume proportion of alveolar duct air, as we have defined it, would decrease. This did not occur in our experiment although we have had evidence for such an adaptive change in rats subjected to pneumonectomy at 12 weeks of age. ${ }^{19}$ We have assumed that the upper lobe, which was intended for biochemical assessment of lung growth, had undergone the same change as the lung as a whole. This may not have been the case, so that the response in terms of alveolar number and surface area may not have been as complete as it appears. This may be offset by our projection of mean number of alveoli per unit volume derived from three lobes to the whole lung. As indicated below, the lower lobe (which in any event is the largest lobe) may have expanded most and thus total alveolar number may be underestimated. However, it is clear that an 
extensive response occurs in the dog which is more complete than in the rat where a similar assumption was made. ${ }^{19}$ The lower lobe appears to respond more completely in that it had significantly more alveoli per unit volume than either the middle or the cardiac lobe, and the average inter-alveolar wall distance and the mean alveolar transection length ( $\mathrm{L}_{m}$ times alveolar air proportion) were smaller. Further, the cardiac lobe had significantly fewer alveoli per unit volume than the cardiac lobe of control animals suggesting an incomplete response. It has been suggested that stretch is the primary stimulating factor to the adaptive response since the response can be reduced or abolished by plombage of the pleural cavity on the side of the pneumonectomy. ${ }^{2} 912$ Although we have no data concerning individual total volumes, it may be that different mechanical stresses occur on the lobes of the lung after pneumonectomy and thus it may be that the lower lobe is stretched the most as it herniates through the incomplete mediastinum of the dog. It therefore undergoes a more complete adaptive response. It seems unlikely that increased blood flow, increased ventilation or the recently described postpneumonectomy serum factor ${ }^{25}$ would produce an uneven lobar response. Variation of response in the lobes were noted in the rat ${ }^{19}$ but not in the rabbit. ${ }^{10}$ Since active lung growth and alveolar multiplication occurred between nine and 20 weeks of age, the adaptive response appears to be a speeding up of this process.

This work was supported by the Medical Research Council of Canada, Grant no MA7124.

\section{References}

1 Addis T. Compensatory hypertrophy of the lung after unilateral pneumonectomy. J Exp Med 1928; 47:51-6.

2 Cohn R. Factors affecting postnatal growth of the lung Anat Rec 1938; 75:195-205.

3 Sery Z, Keprt E, Obrucnik M. Morphometric analysis of late adaptation of the residual lung following pneumonectomy in young and adult rabbits. J Thorac Cardiovasc Surg 1969; 57:549-57.

4 Romanova LK. Regenerative hypertrophy of the lungs in rats after one stage removal of the entire left lung and the diaphragmatic lobe of the right lung. Bull Exp Biol Med 1961; 50:1192-7.

5 Romanova LK, Leikina EM, Antipova KK. Nucleic acid synthesis and mitotic activity during development of compensatory hypertrophy of the lung in rats. Bull Exp Biol Med 1967; 63:303-6.

6 Buhain WJ, Brody JS. Compensatory growth of the lung following pneumonectomy. J Appl Physiol 1973 35:898-902.

7 Tartter PI, Goss RJ. Compensatory pulmonary hypertrophy after incapacitation of one lung in the rat. J Thorac Cardiovasc Surg 1973; 66:147-52.

8 Nattie EE, Wiley CW, Bartlett D Jr. Adaptive growth of the lung following pneumonectomy in rats. J Appl Physiol 1974; 37:491-5.

9 Cowan MJ, Crystal RG. Lung growth after unilateral pneumonectomy: quantitation of collagen synthesis and content. Am Rev Respir Dis 1975; 111 :267-77.

10 Langston C, Sachdeva P, Cowan MJ, Haines J, Crystal RG, Thurlbeck WM. Alveolar multiplication in the contralateral lung after unilateral pneumonectomy in the rabbit. Am Rev Respir Dis 1977; 115:7-13.

11 Boatman ES. A morphometric and morphological study of the lungs of rabbits after unilateral pneumonectomy. Thorax $1977 ; 32: 406-17$.

12 Fisher JM, Simnett JD. Morphogenetic and proliferative changes in the regenerating lung of the rat. Anat Rec 1973; 176:389-95.

13 Bremer JL. The fate of the remaining lung after lobectomy or pneumonectomy. J Thorac Surg 1936; 6:336-43.

14 Longacre JJ, Johansmann R. An experimental study of the fate of the remaining lung following total pneumonectomy. J Thorac Surg 1940; 10:131-49.

15 Cohn R. The postnatal growth of the lung. J Thorac Surg 1940; 9:274-7.

16 Reinhoff WF Jr, Reichert FL, Heuer GJ. Compensatory changes in the remaining lung following total pneumonectomy. Bull Johns Hopkins Hosp 1935; 57:373-83.

17 Gnavi M, Pansa E, Anselmetti G. L'accrescimento e la rigenerazione del polmone (Ricerche sperimentali). Minerva Chir 1970; 25:1491-504.

18 Burri PH, Sehovic S. The adaptive response of the rat lung after bilobectomy. Am Rev Respir Dis 1979; 119:769-77.

19 Holmes C, Thurlbeck WM. Normal lung growth and response following pneumonectomy in the rat at different ages. Am Rev Respir Dis 1979; 120:1125-36.

20 Burri PH, Dbaly J, Weibel ER. The postnatal growth of the rat lung. I. Morphometry. Anat Rec 1974; 178:711-30.

21 Simnett JD. Stimulation of cell division following unilateral collapse of the lung. Anat Rec 1974; $180: 681-6$.

22 Inselman LS, Mellins RB, Brasel J. Effect of lung collapse on compensatory lung growth. $J$ Appl Physiol 1977; 43:27-31.

23 Campbell H, Tomkeieff SI. Calculation of the internal surface of a lung. Nature 1952; 170:117.

24 Weibel ER. Morphometry of the human lung. New York: Academic Press, 1963.

25 Smith BT, Galaugher W, Thurlbeck WM. Serum from pneumonectomised rabbits stimulates alveolar type II cell proliferation in vitro. Am Rev Respir Dis $1980 ; 121: 701-7$. 